\title{
Computed Tomography Characterization of Emphysema in Combined Pulmonary Fibrosis and Emphysema (CPFE) and its Correlation with Lung Cancer with Comparison to Chronic Obstructive Pulmanory Disease (COPD)
}

Jianxing Qiu ( $\sim$ qjx761225@126.com )

Peking University First Hospital

Ligong Nie

Peking University First Hospital

Yan Xiong

Peking University First Hospital

\section{Research Article}

Keywords: Computed tomography(CT), Emphysema, combined pulmonary fibrosis and emphysema (CPFE), chronic obstructive pulmonary disease (COPD), lung cancer

Posted Date: October 15th, 2021

DOl: https://doi.org/10.21203/rs.3.rs-956286/v1

License: (a) (i) This work is licensed under a Creative Commons Attribution 4.0 International License. Read Full License 


\section{Abstract}

Purpose: To investigate imaging features of emphysema on high-resolution computed tomography (HRCT) in combined pulmonary fibrosis and emphysema (CPFE) and its correlation with lung cancer, with comparison to chronic obstructive pulmonary disease (COPD).

Methods: 160 consecutive patients (80 CPFE and 80 COPD ) were analyzed retrospectively. The HRCT imaging features of the two groups were compared, and the correlation between factors underlying CPFE and the occurrence of lung cancer was analyzed.

Results: We found paraseptal emphysema to be the more common form of emphysema in CPFE (38.75\%), with an incidence statistically higher than that of COPD $\left(X^{2}=14.462, p=0.001\right)$. The extent of emphysema in each lung lobe in the CPFE group was statistically less than that in the COPD group $(p<0.01)$. Homogeneous emphysema was common in both the CPFE (73.8\%) and COPD groups (52.5\%), and it showed a higher incidence in CPEF group $\left(\chi^{2}=7.760, p=0.004\right)$. Homogeneous emphysema also showed significantly high correlation to lung cancer $\left(\chi^{2}=9.298, p=0.004\right)$. The incidence of lung cancer in the CPFE group $(20 \%)$ was higher than that in the COPD group $(8.8 \%)\left(\chi^{2}=4.113, p=0.035\right)$. There was a linear relationship between the incidence of lung cancer and the degree of pulmonary interstitial fibrosis and years of smoking in CPFE patients $\left(\chi^{2}=6.679, p=0.01^{*}, b=0.148\right)$.

Conclusion: Different emphysema features showed between CPFE and COPD, and CPFE showed higher incidence of lung cancer. Homogenous emphysema, severity of damage caused by interstitial fibrosis and the number of smoking years have high relationship with incidence of lung cancer in CPFE.

\section{Introduction}

Combined pulmonary fibrosis and emphysema (CPFE) is a clinical entity that has been increasingly diagnosed over the last two decades $[1,2]$ and is broadly characterized by upper lobe emphysema and lower lobe fibrosis $[3,4]$. The upper lobe emphysema contributes to a static volume and late phase in the forced volume test. In contrast, the lower lobe fibrotic portion contributes to early phase flow in the flow volume curve, and the KL-6 value (a blood marker of pulmonary fibrosis) is usually highly elevated [5].

The co-existence of pulmonary fibrosis and emphysema is considered to be an independent syndrome having a specific disease progression, and CPFE is frequently complicated by pulmonary hypertension, acute lung injury, and lung cancer, especially non-small cell lung cancer (NSCLC) [6-8]. Previous studies have shown the severity of fibrosis have correlation with prognosis in CPFE. Prognosis is generally poor, and studies have shown that forced vital capacity (FVC) and fibrosis scores (FS) can be used to predict survival in biopsy-confirmed CPFE $[9,10]$. However, few studies have explored the correlation between emphysema features and lung cancer in CPFE.

The two most prevalent forms of emphysema in CPFE are paraseptal emphysema, and bullae, whose prevalence rates among CPFE patients have been reported to be $93 \%$, and $54 \%$, respectively [11]. Clinically, emphysema was also commonly seen in chronic obstructive pulmanory disease (COPD), and 
centrilobular emphysema showed more common in COPD [9, 12]. However, few studies [13] have explored the detailed characterisitics of emphysema between the two and compared the incidence of lung cancer.

Therefore, for better differentiation in CPFE and COPD and deeper understanding in prognosis in CPFE, in this retrospective cohort study, we investigated the emphysema features including types, volume and uniformity in CPFE, with COPD as comparison, and we also investigated the possible factor correlating to lung cancer including emphysema types and uniformity with multi-factor statistical analyses.

\section{Methods}

\section{Patient population}

This retrospective study was approved by the local ethics committee board (Peking University First Hospital Ethics commitment, and the number of ethics was 2017[1382]) with a waiver of written informed consent. The methods were carried out in accordance with the Declaration of Helsinki.

A total of 160 patients diagnosed with either CPFE or COPD by a multiple team discipline (MDT) of radiologists and pulmonologists from Jan 2013 to May 2019 were included in this study. The CPFE cohort (80 out of 160) was the observation group, and the COPD cohort (80 out of 160) was the control group. Exclusion criteria included any other respiratory diseases, missing information, poor image quality, or other factors resulting in insufficient diagnostic confidence. The smoking history was recored for every participant.

\section{Diagnostic criteria}

We used CT-based diagnostic criteria to diagnose emphysema and pulmonary fibrosis.

Emphysema is characterized as having cystic lung lesions with low-density shadows and a clear boundary. There is no wall structure and only a thin visible wall $(<1 \mathrm{~mm})$, and the diameter of the pulmonary bullae is greater than $1 \mathrm{~cm}$. Pulmonary fibrosis is characterized as having grid and honeycombing shadows predominating in the peripheral pulmonary and lower pulmonary areas; stretch bronchiectasis with a small amount of local ground glass opacity and/or consolidation is also seen. All the diagnoses were made by two senior radiologists who were expertise in pulmonary field in consensus.

Both groups of patients underwent HRCT examinations, using a full-body CT scanner (manufacturer GE). The following scanning parameters were used: voltage $120 \mathrm{KV}$, current automatic adjustment, pitch 1.375, slice thickness $1.25 \mathrm{~mm}$, slice spacing $1 \mathrm{~mm}$. Patients were in a supine position throughout the scan. Breath-holding training was routinely given to patients before scanning. The scan coverage was from the thoracic inlet to the top of the diaphragm.

All the patients were undergone pulmonary functional tests, and the final diagnoses of CPFE and COPD were confirmed by the MDT of sophisticated radiologists and pulmonologists

\section{Emphysema volume}


CT post-processing technology was used in the determination of emphysema volume. Thoracic VCAR is a non-invasive CT image analysis software package, which may be used in conjunction with CT lung images to aid in the assessment of thoracic disease (emphysema, COPD) diagnosis and management. In this study, thoracic VCAR software was utilized to obtain the emphysema volume of the left and right lungs and each lung lobe. When the difference in the volume percentage of any one of the lung lobes was greater than $10 \%$, it was defined as heterogeneous emphysema (Figure 1a). If this was not the case, it was defined as homogeneous emphysema (Figure 1b).

The degree of interstitial fibrosis was characterized in the three groups based on the imaging criteria, including ground-glass opacity, thickened leaflet interval, grid shadow, honeycomb lung, and stretch bronchiectasis (Figure 2).

\section{Statistical analyses}

Data were analyzed using SPSS program version 18.0. The patient demographic data were analyzed first to identify any statistical differences between the CPFE and COPD groups. Emphysema volume and emphysema types with and without the presence of lung cancer were compared between these groups. In addition, the relationship between multiple factors (gender, age, smoking status, emphysema volume uniformity, emphysema type, pulmonary interstitial fibrosis, and years of smoking) and the presence of lung cancer was analyzed.

All measurements are presented as average \pm standard deviation $(X \pm S)$, based on the descriptive statistics. All data evaluate normal distributions. Counting data is expressed as percentages (\%). Chi-square tests were performed, and a $p<0.05$ indicates that the differences were statistically significant. A Chi-square test of association was used to evaluate the linear correlation of pulmonary interstitial fibrosis and the presence of lung cancer or smoking status in the CPFE cohort.

\section{Results}

\section{Demographic data}

For the CPFE observation cohort, there were 72 males and 8 females, and the average age were $(70.5 \pm 9.6)$ years (ranging from 48 to 88 years). For the COPD control group, there were 74 males and 6 females, and the average age were $(72.6 \pm 11.2)$ years (ranging from 45 to 101 years). There were no statistical significance in the demographic differences between the two groups (Supplementary 1).

\section{Comparison of CPFE and COPD cohorts: Emphysema types characterized by HRCT}

The most common type of emphysema in the CPFE cohort was the paraseptal type, followed by the mixed type, and the incidences for both types were statistically higher than for those in the COPD group. The 
COPD was dominated by the centrilobular type at a statistically higher level than for the CPFE group $(p<0.05)$ (Table 1, Figure 3).

Table 1

Emphysema volume and uniformity comparsion between CPFE and COPD HRCT

\begin{tabular}{|lllll|}
\hline Group & Centrilobular & Paraseptal type & Full leaflet type & Mixed type \\
\hline Observation $(n=80)$ & $22(27.50 \%)$ & $31(38.75 \%)$ & $1(1.25 \%)$ & $26(32.50 \%)$ \\
\hline Control $(n=80)$ & $54(67.50 \%)$ & $10(12.50 \%)$ & $2(2.50 \%)$ & $14(17.50 \%)$ \\
\hline$t / \chi^{2}$ & 25.664 & 14.462 & 0.340 & 4.800 \\
\hline$P$ & $0.001^{*}$ & $0.001^{*}$ & 0.50 & $0.02^{*}$ \\
\hline
\end{tabular}

$P$ value with * suggested statistical significance.

\section{Comparison of CPFE and COPD cohorts: Emphysema volume and uniformity}

The emphysema volumes of both the left and right lung were significantly lower in CPFE group $(p<0.01)$, and also showed significantly lower in each lung lobe in CPFE group $(p=0.001)$, compared with the COPD group.

In the CPFE group, 59 cases (incidence of 73.8\%) were homogeneous emphysema, while 21 cases were heterogeneous. In the COPD group, 42 cases (incidence of 52.5\%) were homogeneous emphysema, while 38 cases were heterogeneous. Thus, homogeneous emphysema had a higher incidence in CPEF group. The Chi-square test also confirmed that the incidence of homogeneous emphysema in the CPFE group was significantly higher than that of COPD group $\left(\chi^{2}=7.760, p=0.004<0.01\right)$ (Table 2).

Table 2

Emphysema volume comparison between $\mathrm{CPFE}$ and $\mathrm{COPD}(\mathrm{X} \pm \mathrm{S})$

\begin{tabular}{|llllllll|}
\hline Group & $\begin{array}{l}\text { left lung } \\
\text { (whole) }\end{array}$ & $\begin{array}{l}\text { Upper } \\
\text { lobe Left } \\
\text { lung }\end{array}$ & $\begin{array}{l}\text { Lower } \\
\text { lobe Left } \\
\text { lung }\end{array}$ & $\begin{array}{l}\text { right lung } \\
\text { (whole) }\end{array}$ & $\begin{array}{l}\text { Upper lobe } \\
\text { Right lung }\end{array}$ & $\begin{array}{l}\text { Mid lobe } \\
\text { Right } \\
\text { lung }\end{array}$ & $\begin{array}{l}\text { Lower } \\
\text { lobe Right } \\
\text { lung }\end{array}$ \\
\hline CPFE & $5.04 \pm 4.55$ & $5.15 \pm 4.58$ & $2.16 \pm 2.11$ & $5.16 \pm 4.72$ & $4.62 \pm 4.38$ & $2.35 \pm 2.33$ & $2.27 \pm 2.24$ \\
\hline COPD & $8.90 \pm 8.46$ & $9.78 \pm 9.73$ & $5.99 \pm 5.83$ & $9.08 \pm 8.90$ & $10.22 \pm 10.07$ & $6.92 \pm 6.76$ & $4.88 \pm 4.67$ \\
\hline t & -3.597 & -3.670 & -5.505 & -3.233 & -4.386 & -5.175 & -4.355 \\
\hline P & $0.001 *$ & $0.001 *$ & $0.001 *$ & $0.001^{*}$ & $0.001^{*}$ & $0.001^{*}$ & $0.001^{*}$ \\
\hline \multicolumn{7}{|l}{$P$ value with * suggested statistical significance. } \\
\hline
\end{tabular}




\section{Comparison of CPFE and COPD cohorts: Lung cancer incidence}

Sixteen cases of lung cancer were reported in the CPFE group, compared to 7 cases in the COPD group. The pathological subtypes were squamous cell carcinoma (CPFE, $n=7 ; \operatorname{COPD}, n=4$ ), lung adenocarcinoma ( $C P F E, n=6 ; C O P D, n=3)$, small cell lung cancer ( $C P F E, n=2 ; C O P D, n=0)$, and large cell lung cancer (CPFE, $\mathrm{n}=1 ; \operatorname{COPD}, \mathrm{n}=0)$. The incidence of lung cancer was significantly higher in the CPFE group $(20.0 \%)$ than in the COPD group $(8.75 \%)\left(x^{2}=4.113, p=0.035<0.01\right)$. Squamous cell carcinoma $(43.8 \%)$ and adenocarcinoma (37.5\%) were the most common subtypes in the CPFE group.

\section{Correlation between multi-factors and lung cancer in the CPFE group: Lung cancer incidence and characteristics in CPFE patients}

The analysis of correlation between multi-factors and lung cancer incidence revealed a lack of gender difference was observed $(p>0.05)$. Age, smoker status and emphysema types did not have significant impact on lung cancer incidence ( $p>0.05$ ), but the uniformity of emphysema correlated with lung cancer incidence. Specifically, homogeneous emphysema patients were more likely to develop lung cancer $(42.6 \%)$ than were the patients with heterogeneous emphysema (11.9\%). (Table 3) 
Table 3

Correlation between multi-factors and lung cancer in the CPFE group

\begin{tabular}{|c|c|c|c|c|c|c|c|c|}
\hline \multirow[t]{2}{*}{ Variables } & & \multirow[t]{2}{*}{$\begin{array}{l}\text { No.of } \\
\text { Cases }\end{array}$} & \multicolumn{2}{|c|}{$\begin{array}{l}\text { Incidence of } \\
\text { Lung Caner }\end{array}$} & \multicolumn{2}{|l|}{ Ratio(\%) } & \multirow[t]{2}{*}{$\chi^{2}$} & \multirow[t]{2}{*}{$\mathbf{P}$} \\
\hline & & & Yes & No & $\begin{array}{l}\text { With } \\
\text { Lung } \\
\text { Cancer }\end{array}$ & $\begin{array}{l}\text { Without } \\
\text { Lung } \\
\text { Cancer }\end{array}$ & & \\
\hline \multirow[t]{2}{*}{ Age(years) } & $<60$ & 6 & 1 & 5 & 16.67 & 83.33 & \multirow[t]{2}{*}{0.045} & \multirow[t]{2}{*}{0.655} \\
\hline & $\geq 60$ & 74 & 15 & 59 & 20.27 & 79.73 & & \\
\hline \multirow[t]{2}{*}{ Gender } & Male & 72 & 14 & 58 & 19.44 & 80.56 & \multirow[t]{2}{*}{0.139} & \multirow[t]{2}{*}{0.504} \\
\hline & Female & 8 & 2 & 6 & 25.00 & 75.00 & & \\
\hline \multirow{2}{*}{$\begin{array}{l}\text { Smoking } \\
\text { Status }\end{array}$} & Yes & 66 & 14 & 52 & 21.21 & 78.79 & \multirow[t]{2}{*}{0.346} & \multirow[t]{2}{*}{0.432} \\
\hline & No & 14 & 2 & 12 & 14.29 & 85.71 & & \\
\hline \multirow{2}{*}{$\begin{array}{l}\text { Emphysema } \\
\text { Homogeneity }\end{array}$} & Homogeneous & 21 & 9 & 12 & 42.56 & 57.14 & \multirow[t]{2}{*}{9.298} & \multirow[t]{2}{*}{0.004} \\
\hline & Heterogenous & 59 & 7 & 52 & 11.86 & 88.14 & & \\
\hline \multirow{5}{*}{$\begin{array}{l}\text { Emphysema } \\
\text { Types }\end{array}$} & Paraseptal & 31 & 8 & 23 & 25.81 & 74.19 & \multirow[t]{4}{*}{1.295} & \multirow[t]{4}{*}{0.730} \\
\hline & Mixed & 26 & 4 & 22 & 15.38 & 84.62 & & \\
\hline & lobular central & 22 & 4 & 18 & 18.18 & 81.82 & & \\
\hline & Full leaflet & 1 & 0 & 1 & 0.00 & 100.00 & & \\
\hline & Sum & 80 & 16 & 64 & 20.00 & 80.00 & & \\
\hline
\end{tabular}

\section{Correlation between multi-factors and lung cancer in the CPFE group: The correlation of lung cancer to pulmonary interstitial fibrosis and smoking history}

There was a linear relationship between the incidence of lung cancer and the degree of pulmonary interstitial fibrosis and years of smoking in CPFE patients. The incidence of lung cancer increased with the severity of interstitial fibrosis and the duration of smoking. For every severity degree increase of interstitial fibrosis or every 10 years of smoking history, the cancer incidence rose by $14.8 \%$ or $14.1 \%$, respectively. (Table 4, Supplementary 2). 
Table 4

Relationship between the incidence of lung cancer and the degree of pulmonary interstitial fibrosis in CPFE patients

\begin{tabular}{|llll|}
\hline $\begin{array}{l}\text { Degree of pulmonary interstitial } \\
\text { fibrosis }\end{array}$ & $\begin{array}{l}\text { No of } \\
\text { Cases }\end{array}$ & $\begin{array}{l}\text { Incidence of lung cancer } \\
(\#)\end{array}$ & $\begin{array}{l}\text { Lung cancer } \\
\text { rate(\%) }\end{array}$ \\
\hline Mild & 25 & 2 & 8.00 \\
\hline Moderate & 34 & 6 & 17.65 \\
\hline Severe & 21 & 8 & 38.10 \\
\hline Sun & 80 & 16 & $20.00 \%$ \\
\hline & $\chi^{2}=6.679, p=0.01^{*}, b=0.148$ & \\
\hline$P$ value with * suggested statistical significance. & \\
\hline
\end{tabular}

\section{Discussion}

In our study, we investigated the detailed imaging features of emphysema in CPFE, with comparsion to COPD, and our results showed paraseptal emphysema was the most common form in CPFE, with an incidence statistically higher than that of COPD $(p=0.001)$. Homogeneous emphysema was common in both the CPFE (73.8\%) and COPD groups (52.5\%), and it showed a higher incidence in CPEF group $(p=0.004)$. The extent of emphysema in each lung lobe in the CPFE group was statistically less than that in the COPD group $(p<0.01)$.

Due to the histopathological heterogeneity of CPFE, researchers often rely on HRCT for the diagnosis of $\mathrm{CPFE}$, rather than using a pathological diagnosis [14-17]. HRCT can be used to visualize early changes in emphysema, as well as the in-depth details of interstitial pneumonia. HRCT thus plays a fundamental role in diagnosis of CPFE syndrome. Choi et al. [17] suggested the following diagnostic criteria based on HRCT: an area of emphysema with a reduced translucency clearly demarcated from adjacent normal lung tissue with a very thin wall $(<1 \mathrm{~mm})$ or no wall, and/or multiple pulmonary bullae $(>1 \mathrm{~cm})$ in the upper lobe. Centrilobular emphysema is a long-term, progressive lung disease and is considered to be a form of COPD, and studies $[9,12]$ have shown that centrilobular emphysema and/or bullous emphysema occurring predominantly in the upper lung is seen as a focal low-density area clearly demarcated from normal lung tissue, with visibly thin walls $(<1 \mathrm{~mm})$ or no wall.

Paraseptal emphysema (seen as low-attenuation areas in the subpleural zone) has been described in a majority of CPFE reports [1], and Araki [11] suggest that paraseptal emphysema is a typical feature of CPFE. However, determination of the emphysema type in CPFE is often very difficult because of alteration of its features due to coexisting fibrosis [18]. In spite of this difficulty, the presence of thick-walled large cysts $-2 \mathrm{~cm}$ or more in diameter and delimitated by a wall $1 \mathrm{~mm}$ or more in thickness - in an area of the lung where reticulation is present, is considered to be one of the characteristic features of CPFE [19]. Based on the analysis of emphysema types in CPFE patients, this current study revealed that paraseptal type 
emphysema is the most common, a finding consistent with other studies $[11,13]$. And we also used COPD as control to further pove the emphysema differences between the two enteties.

In our study, by using the thoracic VCAR post-processing software, we found that homogeneous emphysema was the main type in CPFE patients. This research has not been conducted before between CPFE and COPD. In addition, the emphysema volume was lower than that of COPD patients. This may be due to the different pathological mechanisms of emphysema formation by the two diseases. Although both can lead to poor alveolar elasticity, valve action caused by chronic bronchiolitis might also contribute to the pathogenesis of COPD. A larger sample study is required to confirm this hypothesis.

This study also explored the incidence of lung cancer in CPFE patients. Our results show that CPFE patients are more likely to develop lung cancer, compared with COPD patients, with squamous cell carcinoma being the most commonly seen. These results are consistent with previous studies published by Kwak et al. [20]. Upon analyzing the relationship between multiple factors of CPFE and lung cancer, we found that lung cancer incidence is higher in homogeneous emphysema patients and increases both with the severity of pulmonary interstitial fibrosis and the number of years of smoking. We speculated that homogeneous emphysema, severe fibrosis, and length of smoking history are the principal risk factors for lung cancer in CPFE patients. The diffuse pulmonary interstitial fibrosis seen in CPFE often presents as reticular blurry shadows, honeycomb patterns, distortion of alveolar structures in the subpleural and lower lobe, and/or traction bronchial or bronchiolar dilation $[13,19]$. Focal ground glass opacity and/or alveolar consolidation may also occur but is not the primary manifestation. Occasionally, ground-glass opacity can be the only evidence of interstitial lung disease, and in this situation, lung biopsy becomes necessary [21]. In a few cases, pulmonary nodules and consolidation have also been found in CPFE, findings which are correlated with a higher incidence of lung cancer [20].

Previous studies have shown that smoking is closely related to the occurrence of CPFE and lung cancer. However, further research is needed to describe the correlation of homogeneous emphysema, degree of fibrosis, and lung cancer incidence. This information would contribute to both earlier detection of lung cancer and earlier treatment of patients, making increased survival of CPFE patients possible.

The limitations of this study include small sample size, and lack of in-depth characterization of interstitial fibrosis. In future study, we should conduct further investigation.

\section{Conclusions}

Pulmonary interstitial fibrosis with emphysema (CPFE) features unique imaging characteristics. Different emphysema features showed between CPFE and COPD, and CPFE showed higher incidence of lung cancer. Homogenous emphysema, severity of damage caused by interstitial fibrosis and the number of smoking years have high relationship with incidence of lung cancer in CPFE. Radiologists treating patients with CPFE should be alert to the high incidence of lung cancer in this population. Clinical manifestations and imaging should also be included when managing CPFE patients. 


\section{Abbreviations}

COPD: chronic obstructive pulmonary disease

CPFE: combined pulmonary fibrosis and emphysema

HRCT: high-resolution computed tomography

NSCLC: non-small cell lung cancer

FVC: forced vital capacity

FS: fibrosis scores

MDT: multiple team discipline

\section{Decalration}

\section{Ethics approval and consent to participate}

Our study was approved by an institutional review board (Peking University First Hospital Ethics commitment, and the number of ethics was 2017[1382]). The need for written informed consent was waived by the institutional review board due to the retrospective design of the study.

The methods were carried out in accordance with the Declaration of Helsinki.

\section{Consent for publication}

All the authors consent for the publication.

\section{Availability of data and material}

The datasets used and/or analysed during the current study available from the corresponding author on reasonable request.

\section{Competing interests}

There is no competing interests among authors.

\section{Funding}

$\mathrm{N} / \mathrm{A}$

\section{Authors' contributions}

Jianxing Qiu: Data curation, Writing- editing, Visualization, Investigation. 
Ligong Nie: Data curation, Writing- Original draft preparation.

Yan Xiong: Visualization, Investigation.

\section{Acknowledgements}

N/A

\section{References}

1. Ciccarese F, Attina D, Zompatori. Combined Pulmonary Fibrosis and Emphysema (CPFE): What Radiologists Should Know. Radio Med. 2016;121(7):564-572.

2. Jankowich MD, Rounds S. Combined pulmonary fibrosis and emphysema alters physiology but has similar mortality to pulmonary fibrosis without emphysema. Lung. 2010;188:365-373.

3. Amariei DE, Dodia N, Deepak J, et al. Combined Pulomonary Fibrosis and Emphysema: Pulmonary Function Testing and a Pathophysiology Perspective. Medicina (Kaunas). 2019;55(9):580.

4. Papaioannou Al, Kostikas K, Manali ED, et al. Combined Pulmonary Fibrosis and Emphysema: The Many Aspects of a Cohabitation Contract. Respir Med. 2016;117:14-26.

5. Takai D. Combined Pulmonary Fibrosis and Emphysema (CPFE): Limitation of Usual Lung Function Test and Challenge at Practice. Rinsho Byori. 2014;62 (12):1218-1225.

6. Lin H, Jiang S. Combined Pulmonary Fibrosis and Emphysema (CPFE): An Entity Different From Emphysema or Pulmonary Fibrosis Alone. J Thorac Dis. 2015;7(4):767-779.

7. Seeger W, Adir Y, Barbera JA, et al. Pulmonary Hypertension in Chronic Ling Diseases. J Am Coll Cardiol. 2013; 62 (25 Suppl).

8. Zhang L, Zhang C, Dong F. Combined Pulmonary Fibrosis and Emphysema: A Retrospective Analysis of Clinical Characteristics, Treatment and Prognosis. BMC Pulm Med. 2016;16 (1):137.

9. Brillet PY, Brillet PY, Cottin V, et al. Combined apical emphysema and basal fibrosis syndrome (emphysema/fibrosis syndrome): CT imaging features and pulmonary function tests. J Radiol. 2009;90:43-51.

10. Moon SW, Park MS, Kim YS. Combined Pulmonary Fibrosis and Emphysema and Idiopathic Fibrosis in Non-Small Cell Lung Cancer: Impact on Survival and Acute Exacerbation. BMC Pulm Med. 2019;19 (1):177.

11. Araki T, Nishino M, Zazueta OE. Paraseptal Emphysema: Prevalence and Distribution on CT and Association with Interstitial Lung Abnormalities. Eur J Radiol. 2015;84(7):1413-1418.

12. Rogliani $P$, Mura M, Mattia $P$, et al. HRCT and histopathological evaluation of fibrosis and tissue destruction in IPF associated with pulmonary emphysema. J Respir Med. 2008;102(12):1753-1761.

13. Kitaguchi Y, Fujimoto K, Hanaoka M, et al. Clinical characteristics of combined pulmonary fibrosis and emphysema. Respirology. 2010;15:265-271. 
14. Cottin V, Nunes $\mathrm{H}$, Brillet PY, et al. Combined pulmonary fibrosis and emphysema: a-distinct underrecognized entity. Eur Respir J. 2005;26(4):586-593.

15. Wand O, Kramer MR. The Syndrome of Combined Pulmonary Fibrosis and Emphysema-CPFE. Harefuah. 2018;157 (1):28-33.

16. Kwiatkowska S. IPF and CPFE-The Two Different Entities or Two Different Presentations of the Same Disease? Adv Respir Med. 2018;86 (1):23-26.

17. Choi SH, Lee HY, Lee KS. The Value of CT for Disease Detection and Prognosis Determination in Combined Pulmonary Fibrosis and Emphysema (CPFE). PLoS One. 2014;9 (9):e107476.

18. Nakata H, Kimoto T, Nakayama T, et al. Diffuse peripheral lung disease: valuation by high-resolution computed tomography. J Radiology. 1985;157(1):181-185.

19. Brillet PY, Cottin V, Letoumelin P, et al. Combined apical emphysema and basal fibrosis syndrome (emphysema/fibrosis syndrome): CT imaging features and pulmonary function tests. J Radiol. 2009;90:43-51.

20. Kwak N, Park C M , Lee J , et al. Lung cancer risk among patients with combined pulmonary fibrosis and emphysema. Respiratory Medicine. 2014;108(3):524-530.

21. Webb WR. Radiology of obstructive pulmonary disease. Am J Roentgenol. 1997;169(3):637-647.

\section{Figures}

\begin{tabular}{|c|c|c|c|c|c|c|c|c|c|}
\hline \multirow{2}{*}{$\begin{array}{c}\text { Range } \\
\text { name }\end{array}$} & \multirow{2}{*}{\begin{tabular}{c|c}
$\begin{array}{c}\text { Range } \\
\text { values }\end{array}$ \\
\end{tabular}} & \multicolumn{4}{|c|}{ Right Lung } & \multicolumn{3}{|c|}{ Left Lung } & \multirow{2}{*}{$\begin{array}{l}\text { Total Lung Volume } \\
\text { Combined Lungs } \\
\end{array}$} \\
\hline & & Right Lung & Upper Lobe & Middle Lobe & Lower Lobe & Left Lung & Upper Lobe & Lower Lobe & \\
\hline$-950 \mathrm{HU}$ & $\begin{array}{c}{[-1024 /} \\
-950] \\
\end{array}$ & $36.2011 \%$ & $46.7168 \%$ & $50.0336 \%$ & $24.0543 \%$ & $34.3646 \%$ & $52.4921 \%$ & $14.1944 \%$ & $35.3101 \% / 2.9741 \mathrm{~L}$ \\
\hline $\begin{array}{c}>- \\
950 \mathrm{HU}\end{array}$ & $\begin{array}{l}{[-950 /} \\
3071]\end{array}$ & $63.7989 \%$ & $53.2832 \%$ & $49.9664 \%$ & $75.9457 \%$ & $65.6354 \%$ & $47.5079 \%$ & $85.8056 \%$ & $64.6899 \% / 5.4486 \mathrm{~L}$ \\
\hline 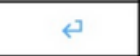 & Total & $4.3363 \mathrm{~L}$ & $1.663 \mathrm{~L}$ & $0.5768 \mathrm{~L}$ & $2.0965 \mathrm{~L}$ & $4.0864 \mathrm{~L}$ & $2.1522 \mathrm{~L}$ & $1.9342 \mathrm{~L}$ & $8.4227 \mathrm{~L}$ \\
\hline \multicolumn{6}{|c|}{$\hookleftarrow$} & \multicolumn{4}{|r|}{$\mathrm{A}$} \\
\hline $\begin{array}{l}\text { Range } \\
\text { name }\end{array}$ & $\begin{array}{l}\text { Range } \\
\text { values }\end{array}$ & \multicolumn{4}{|c|}{ Right Lung } & \multicolumn{3}{|c|}{ Left Lung } & Total Lung Volume \\
\hline 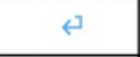 & $\hookleftarrow$ & Right Lung & Upper Lobe & Middle Lobe & Lower Lobe & Left Lung & Upper Lobe & Lower Lobe & Combined Lungs \\
\hline$-950 \mathrm{HU}$ & $\begin{array}{c}{[-1024 /} \\
-950]\end{array}$ & $1.2519 \%$ & $0.4166 \%$ & $3.0181 \%$ & $1.2512 \%$ & $1.1549 \%$ & $0.9437 \%$ & $1.4948 \%$ & $1.2104 \% / 0.0386 \mathrm{~L}$ \\
\hline $\begin{array}{c}>- \\
950 \mathrm{HU}\end{array}$ & $\begin{array}{l}{[-950 /} \\
3071]\end{array}$ & $98.7481 \%$ & $99.5834 \%$ & $96.9819 \%$ & $98.7488 \%$ & $98.8451 \%$ & $99.0563 \%$ & $98.5052 \%$ & $98.7896 \% / 3.1504 \mathrm{~L}$ \\
\hline 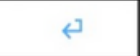 & Total & $1.8237 \mathrm{~L}$ & $0.8994 \mathrm{~L}$ & $0.4255 \mathrm{~L}$ & $0.4987 \mathrm{~L}$ & $1.3654 \mathrm{~L}$ & $0.8421 \mathrm{~L}$ & $0.5233 \mathrm{~L}$ & $3.189 \mathrm{~L}$ \\
\hline
\end{tabular}



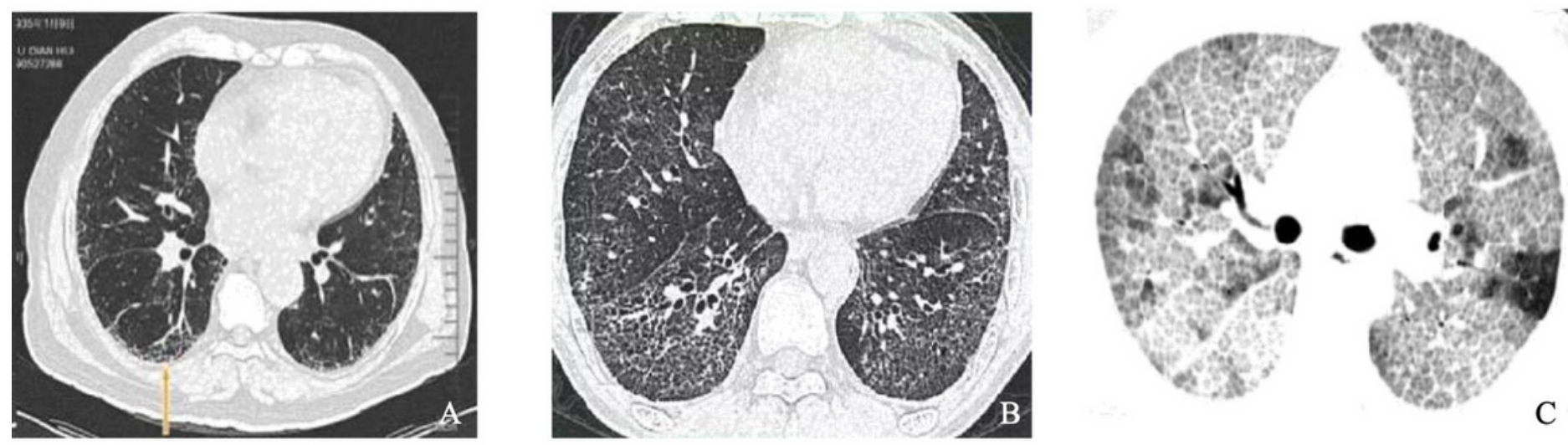

\section{Figure 2}

Interstitial fibrosis A-Mild: only a small amount of thickening of the subpleural lobular septa; most of the lung fields are clean. B-Moderate: thickening of the lobular septa and thickening of the intralobular septa with some ground-glass opacity and stretch bronchiectasis. C-Severe: Diffuse lobular septum and thickened interlobular septum in both lungs, with ground-glass and stretch bronchiectasis, occupying most of the lung tissue. Each scan was evaluated by two experienced radiologists independently.

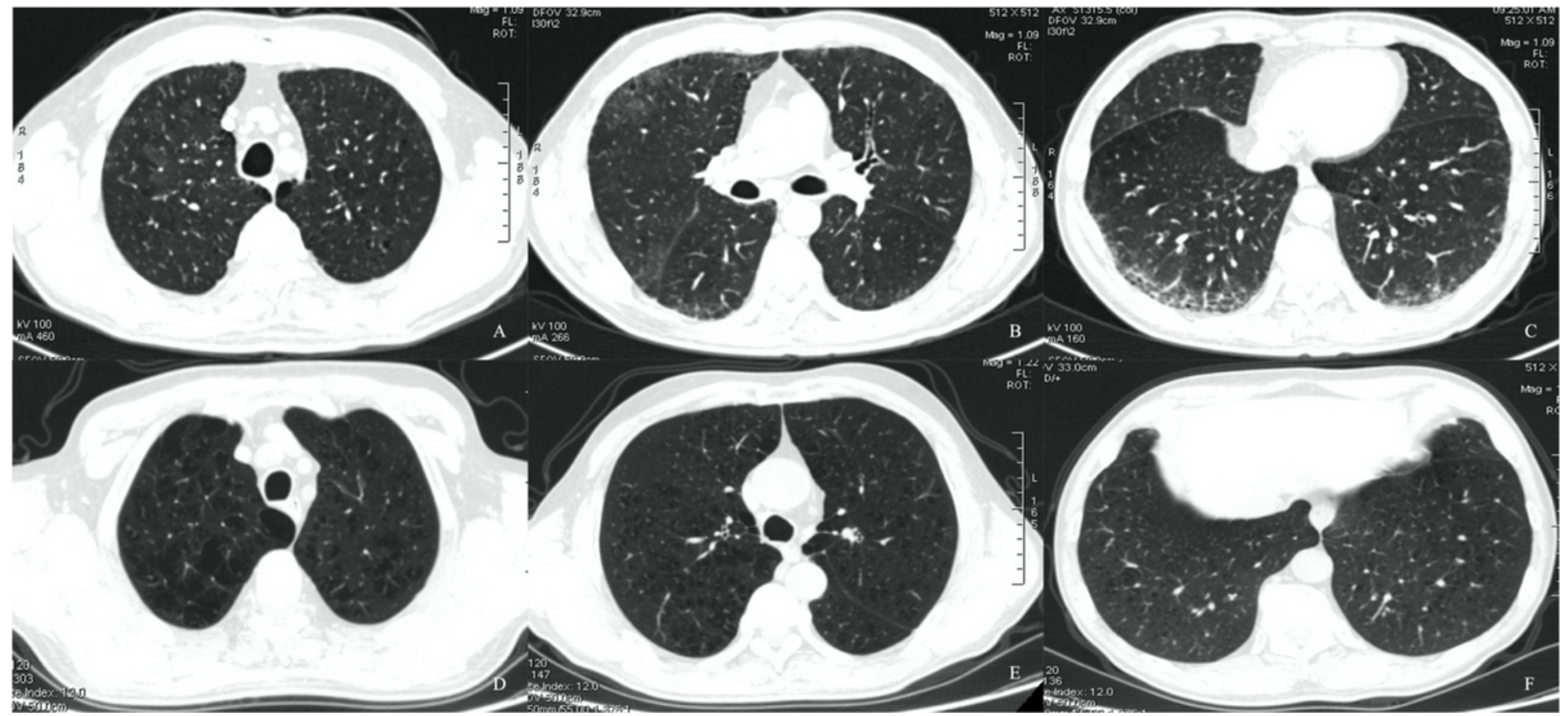

\section{Figure 3}

Different emphysema types in CPFE and COPD A-C: A CPFE patient. Paraseptal emphysema was dominant in bilateral lungs. D-F: A COPD patient. Centrolobular emphysema was dominant in bilateral lungs. 